\title{
Impact of both desiccation and exposure to an emergent skin pathogen on transepidermal water exchange in the palmate newt Lissotriton helveticus
}

\author{
Thomas Wardziak ${ }^{1, *}$, Emilien Luquet ${ }^{1,2}$, Sandrine Plenet $^{1}$, Jean-Paul Léna ${ }^{1}$, \\ Laurent Oxarango ${ }^{3}$, Pierre Joly ${ }^{1}$
}

${ }^{1}$ Université de Lyon, UMR 5023 Ecologie des Hydrosystèmes Naturels et Anthropisés, Université Lyon 1, ENTPE, CNRS, 6 rue Raphaël Dubois, 69622 Villeurbanne, France

${ }^{2}$ Centre d'Ecologie Fonctionnelle et Evolutive, UMR 5175 CNRS, 1919 route de Mende, 34293 Montpellier Cedex 5, France ${ }^{3}$ LTHE, Université de Grenoble, BP 53, 38041 Grenoble Cedex, France

\begin{abstract}
Amphibians are the vertebrate group most affected by global change. Their highly permeable skin is involved in maintaining homeostasis (e.g. water and electrolyte equilibrium), which makes them particularly vulnerable to climate warming and skin pathogens. This study focused on the impacts of both desiccation (as a potential consequence of climate warming) and exposure to Batrachochytrium dendrobatidis $(B d)$, an emergent skin pathogen of amphibians. $B d$ causes chytridiomycosis, a lethal skin disease of amphibians, and is responsible for mass mortality events in several regions of the world. Because $B d$ colonizes the superficial layers of the epidermis, it is assumed to affect water transfer across the skin. We investigated the behavioural postures of the palmate newt Lissotriton helveticus expressed in response to desiccation and their influence on transepidermal water loss (TEWL) rate. We also investigated the effects of repeated $24 \mathrm{~h}$ exposure to $B d$ (i.e. every $4 \mathrm{~d}$ for $16 \mathrm{~d}$ ) on the TEWL and ventral water absorption (VWA) rates of these newts. Our results suggest an efficient behavioural water-conserving mechanism, i.e. an 'S'-shaped posture associated with a restricted activity rate, not affected by repeated exposure to $B d$. Similarly, TEWL was not significantly affected in exposed newts. VWA was significantly reduced after just $24 \mathrm{~h}$ exposure to $B d$ without modification until the end of the experiments. Our results suggest that $B d$ could rapidly inhibit rehydration of $L$. helveticus through fungal toxins and disrupt an essential function for survival.
\end{abstract}

KEY WORDS: Batrachochytrium dendrobatidis $\cdot$ Chytrid fungus $\cdot$ Emerging disease $\cdot$ Amphibian skin Evaporative water loss $\cdot$ Water absorption $\cdot$ Osmotic balance $\cdot$ Water-conserving behaviour

\section{INTRODUCTION}

Climate warming and emerging infectious diseases (EIDs) are both major threats affecting biodiversity (Carey 2000, Harvell et al. 2002, Thomas et al. 2004). Climate warming is expected to lead to greater contrasts in rainfall distributions, with longer and more intense drought periods (Solomon et al. 2007). Such environmental changes may lead to detrimental ther- mal and/or hydric conditions for organisms (e.g. shelter loss, intense drought periods with reduced water availability) that prevent them from maintaining homeostasis (e.g. water and electrolyte equilibrium) with direct physiological and functional consequences (Spotila \& Berman 1976, Shoemaker et al. 1992, Spotila et al. 1992). EIDs can result from environmental changes in pathogen habitats, although they can also emerge in new geographical areas (novel patho- 
gen hypothesis; e.g. Laurance et al. 1996, Daszak et al. 1999, Rachowicz et al. 2005). The endemic pathogen hypothesis suggests that environmental changes (biotic and/or abiotic) can drive modifications in life history traits of native pathogens (virulence, survival, dispersal capacity) and/or host susceptibility (e.g. Kiesecker \& Blaustein 1995, Schrag \& Wiener 1995, Carey et al. 1999, Kiesecker et al. 2001, Rachowicz et al. 2005). EIDs can cause sub-lethal damage to hosts (e.g. developmental and physiological abnormalities) leading to the decline of host populations (Pounds et al. 2006, Garner et al. 2009, Blaustein et al. 2012). By disturbing the physiological functions of hosts, EIDs may also reduce the ability of individuals to maintain homeostasis and to respond to environmental change (Luquet et al. 2012). Consequently, climate warming can drive the emergence of infectious diseases, and EIDs can increase the detrimental impacts of climate warming (Garner et al. 2011, Blaustein et al. 2012, Fisher et al. 2012). It is crucial to study these 2 threats to biodiversity in concert in order to understand their detrimental consequences. In this context, our study focused on the impacts of both desiccation (as a potential consequence of climate warming) and exposure to an emergent pathogen in amphibians.

Amphibians are the vertebrate taxon most threatened by global change (Stuart et al. 2004). Their skin represents the key organ involved in maintaining homeostasis. As a consequence, these animals have a highly permeable and heavily vascularized epidermis allowing an efficient pathway for gas exchanges and for water and electrolyte absorption. However, these skin characteristics reduce the water retention ability and make amphibians highly vulnerable to transepidermal evaporative water loss (TEWL; Shoemaker et al. 1992, Spotila et al. 1992, Lillywhite 2006). A major challenge for amphibians in the terrestrial environment is therefore how to limit TEWL rate. TEWL is a passive diffusion process that depends primarily on physical conditions such as temperature and relative humidity of the atmosphere (Shoemaker et al. 1992, Spotila et al. 1992, Lillywhite 2006). Amphibians develop adaptations to limit TEWL rate and to replenish body water loss by evaporation. They show behavioural adaptations like water-conserving postures to reduce the skin area exposed to the atmosphere (e.g. Alvarado 1967, Gehlbach et al. 1969, Pough et al. 1983). A functional adaptation allows active water absorption in the ventral skin regions in contact with moistened substrates (called ventral water absorbtion, VWA). However, VWA efficiency depends on hydric environmental conditions (i.e. substrate water availability; Shoemaker et al. 1992, Spotila et al. 1992, Vi- borg \& Rosenkilde 2004). Consequently, climate warming, with frequent and longer drought events, can expose amphibians to pronounced water imbalance leading to high desiccation risks.

The physiological importance of the skin also makes amphibians extremely sensitive to chytridiomycosis, an emergent skin disease caused by the pathogenic fungus Batrachochytrium dendrobatidis (hereafter $B d$ ). Cutaneous chytridiomycosis is a potentially lethal skin disease of amphibians known to contribute to population decline and mass-mortality events observed worldwide (Berger et al. 1998, Daszak et al. 1999, Bosch et al. 2001). As Bd is restricted to the superficial epidermis (Berger et al. 1998), this pathogen is suspected of affecting transepidermal water transfers. Two major, non-mutually exclusive, mechanisms have been proposed (Berger et al. 1998, 2005, Pessier et al. 1999): (1) epidermal hyperplasia and hyperkeratosis can physically block transepidermal water transfer, and (2) a fungal toxin, or other active compounds released by the pathogen, can interfere with the osmoregulatory functions of the epidermis. Understanding the mechanisms of pathogenesis is an important step to providing explanations on how exposure to or infection with $B d$ can cause such global amphibian declines (Daszak et al. 2003). Few studies have so far focused on the physiological effects of $B d$ on amphibians. Recent laboratory studies suggested impairments in normal skin functions in $B d$-infected frogs, such as electrolyte depletion, osmotic imbalance (Voyles et al. 2007, 2009, 2012, Marcum et al. 2010) and disruption in the ability to rehydrate (Carver et al. 2010). However, physiological responses to $B d$ exposure/infection still remain unclear.

The objective of the study was to quantify the impact of both desiccation events and exposure to $B d$ on transepidermal water exchange (i.e. TEWL and VWA rates) in a urodele species, the palmate newt Lissotriton helveticus, during its terrestrial phase. We further investigated how newt behaviours (waterconserving postures) may influence the TEWL rate and how exposure to $B d$ affects these postures. Palmate newts are excellent models for such a study because this species is (1) active during the warmest months (terrestrial phase), (2) highly sensitive to dehydration due to a high body surface to volume ratio and (3) susceptible to $B d$ in the wild (Dejean et al. 2010). We performed laboratory experiments to test the following hypotheses: (1) palmate newts exposed to desiccating conditions should exhibit restricted activity and specific water-conserving postures, and (2) palmate newts exposed to $B d$ should exhibit disruption in TEWL and/or VWA rates. 


\section{MATERIALS AND METHODS}

\section{Animal collection}

Adult male palmate newts $(n=64$; mean \pm SE body mass: $0.627 \pm 0.016 \mathrm{~g}$, snout-vent length: $2.97 \pm$ $0.02 \mathrm{~cm}$ ) were sampled in May 2010 during their aquatic phase in forest ruts near Mépieu, France $\left(05^{\circ} 26^{\prime} 28^{\prime \prime} \mathrm{E}, 45^{\circ} 43^{\prime} 56^{\prime \prime} \mathrm{N}\right)$. Both Hyla arborea (see Luquet et al. 2012) and Bufo bufo populations (E. Luquet, S. Plénet, J. P. Léna unpubl. data) have been widely sampled (ca. 30 ind. population ${ }^{-1}$ ) at the same sites as newts and at other sites throughout the Isère Département (France), and no $B d$ infection has been detected. As $B d$ is absent from the Isère Département, we are fairly certain that sampled palmate newts were not infected with $B d$ before the experiment began. All individuals from this population were housed in aquaria providing both aquatic and terrestrial environments allowing them to leave the water. When the newts began their terrestrial stage, they were housed individually in plastic boxes $(19 \times 16.5 \times 9.5 \mathrm{~cm})$ lined with moistened cellulose paper, renewed weekly. The boxes were kept in climate-controlled rooms at $20 \pm 1{ }^{\circ} \mathrm{C}, 60 \pm 10 \%$ relative humidity and with a 16:8 light:dark regime. Newts were fed with small crickets ad libitum.

\section{Bd exposure}

Individual newts at the terrestrial stage were randomly assigned to control $(\mathrm{n}=30)$ and $B d(\mathrm{n}=34)$ treatments. We used a Bd IA2004 043 isolate generated from a dead Alytes obstetricans metamorph collected from a mass mortality event in Spain, and known to be highly virulent (Farrer et al. 2011). For the control and $B d$ treatments, newts were transferred to individual plastic Petri dishes with lids (height = $1 \mathrm{~cm}, \varnothing=9 \mathrm{~cm}$ ) filled with $10 \mathrm{ml}$ of tap water to ensure a fully hydrated body mass (i.e. the initial body mass, $\mathrm{W}_{0}$ ) of the animals. To ensure adequate ventilation, the Petri dish lids were pierced with holes. Depending on the treatment, newts were repeatedly exposed to either $5 \mathrm{ml}$ culture, containing a total dose of 15000 to 75000 zoospores at each inoculation (exposed newts), or $5 \mathrm{ml}$ of sterile culture medium (control newts). The newts were exposed for 24 h every $4 \mathrm{~d}$ for $16 \mathrm{~d}$ ( 4 exposures in total). Eight of the 30 control newts died during the second exposure because of an experimental error (i.e. these newts were transferred to unpierced Petri dishes), and 7 of the 34 exposed newts died in the interval between the 2 periods of measure- ments. At the end of the experiment, we collected skin swab samples from 22 control newts (including the 8 dead individuals) and 22 exposed newts (including the 7 dead individuals). We were not able to perform infection detection on all individuals because of financial constraints. No further histological analyses were performed on the dead animals.

We performed real-time PCR to assess the skin swab samples for Bd DNA (Boyle et al. 2004). Extractions were diluted by $1 / 10$ before real-time PCR amplification, performed in duplicate, and with $B d$ genomic equivalent standards of 100, 10, 1, and 0.1 zoospore genome equivalents. All PCRs were replicated twice, and we considered successful amplification in both reactions as a positive signal of $B d$ presence. In the event that only one replicate from any sample did not amplify, this sample was run a third time. If this third amplification attempt did not result in an amplification profile, the sample was scored as negative for infection. No amplification in both replicates was taken as a true negative signal. All exposed newts were ethically euthanized with an overdose of MS222 in accordance with the recommendations of the AVMA Panel on Euthanasia.

\section{Experimental design}

Behavioural responses and transepidermal water exchange (TEWL and VWA rates) of all newts were investigated at 2 periods: after $24 \mathrm{~h}$ (Day $1 ; \mathrm{n}=30$ and 34 for control and exposed newts, respectively) and on Day 16 ( $\mathrm{n}=22$ and 27 for control and exposed newts, respectively) after the initial exposure. All measurements were carried out in a climate chamber $(50 \times 60 \times 80 \mathrm{~cm})$, placed in a climate-controlled room at $20 \pm 1^{\circ} \mathrm{C}$, allowing the relative humidity to be controlled (i.e. $60 \pm 3 \%$ ) using silica gel. In order to perform measurements without any modification of ambient humidity, 2 holes were made in the front wall of the chamber, each equipped with a flexible duct ending in a latex glove. It was thus possible to manipulate the newts without opening the chamber by slipping hands and arms into these ducts.

Expt 1. The purpose of this experiment was to study behavioural responses to desiccation (activity in moves $\mathrm{min}^{-1}$ and postural adjustment, i.e. adoption of ' $\mathrm{S}$ ' or 'I' postures $\mathrm{min}^{-1}$ ) and how exposure to $B d$ affected these behaviours. Each newt was placed in a dry plastic Petri dish ( $\mathrm{h}=2.5 \mathrm{~cm}, \varnothing=9 \mathrm{~cm}$ ) laid on a microbalance (Scaltec sbc 31; $0.001 \mathrm{~g}$ sensitivity). We continuously monitored their behaviour using JWatcher (1.0 version) software for both treatments 
during the desiccation period (see Expt 3 below). Newts with a posture characterized by a relatively straight body with no tail coil were considered to have the 'I'-shaped posture. When the body was huddled up with the tail coiling along it, newts were considered to have the 'S'-shaped posture (Fig. 1). We measured the time spent active relative to total dehydration time (moves $\mathrm{min}^{-1}$ ) and the time spent inactive with the 'I' or ' $\mathrm{S}$ ' posture relative to total inactivity time (adoption of 'S' or 'I' posture $\mathrm{min}^{-1}$ ).

Expt 2. The purpose of this experiment was to evaluate the impact of postural adjustment ('I' versus ' $\mathrm{S}$ ' shape) on the TEWL. For this purpose, we created agar models of palmate newts ( $\mathrm{n}=4$ for each postural adjustment; Fig. 1) using the method of Spotila \& Berman (1976). To obtain replicas similar to our newts, agar models were cast from dead animals frozen in the desired posture and immersed in fluid alginate previously poured into a small plastic container. After hardening of the alginate, the dead newts were removed and moulds filled with a solution of 3\% agar, 97\% water. Each agar model was placed in a dry plastic Petri dish $(\mathrm{h}=2.5 \mathrm{~cm}, \varnothing=$ $9 \mathrm{~cm}$ ) laid on a microbalance (Scaltec sbc 31; $0.001 \mathrm{~g}$ sensitivity). We measured the body mass of agar models every 10 min until $10 \%$ loss of their $\mathrm{W}_{0}$ was reached.
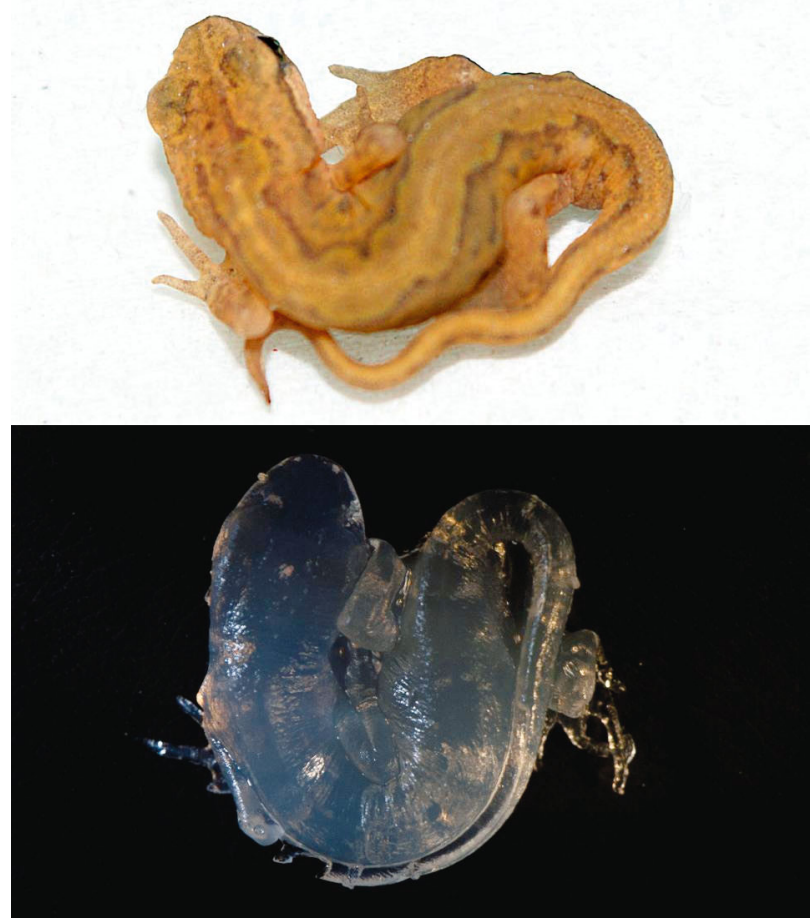

Fig. 1. Lissotriton helveticus. Adult male palmate newt in the 'S'-shaped posture and its agar model. Photographs taken by $\mathrm{T}$. Wardziak and T. Colin
Expt 3. The purpose of this experiment was, simultaneously with the behavioural experiment (see Expt 1 above), to quantify the impact of exposure to $B d$ on transepidermal water exchange (i.e. TEWL and VWA rates). We estimated the TEWL rate by measuring the body mass loss of the newts every 10 min until they reached a $10 \%$ loss of $W_{0}$. To avoid biases due to newts remaining in close contact with the sides of the dish, and thus artificially reducing the TEWL rate, the Petri dish rim was lined with wire mesh. We estimated the VWA rate by placing the newts in Petri dishes filled with $15 \mathrm{ml}$ of tap water allowing them complete ventral absorption, immediately after the dehydration period. We measured body mass every $10 \mathrm{~min}$, over a $60 \mathrm{~min}$ period, by moving newts to the microbalance after removing excess water with absorbent paper.

\section{Statistical analysis}

The first model (Model 1) examined the effects of initial body mass $\left(\mathrm{W}_{0}\right)$, treatment (control or exposed), day of measurement (Day 1 or 16) and their interactions on behavioural responses, i.e. the activity (moves $\mathrm{min}^{-1}$ ) and the postural adjustment (adoption of ' $\mathrm{S}$ ' or ' $\mathrm{I}$ ' posture $\mathrm{min}^{-1}$ ). $\mathrm{W}_{0}$, treatment and day were considered as fixed effects. The second model (Model 2) investigated the effects of $\mathrm{W}_{0}$, postural adjustment (' $\mathrm{I}$ ' or ' $\mathrm{S}$ '), successive measurements made within the desiccation period (time) and their interactions on the TEWL rate of agar models. $\mathrm{W}_{0}$, postural adjustment and time were considered as fixed effects. Both final models (Model 3 for the TEWL rate and Model 4 for VWA rate) examined the effects of $\mathrm{W}_{0}$, treatment, day, time and their interactions on transepidermal water exchange (i.e. TEWL and VWA rates). $\mathrm{W}_{0}$, treatment, day and time were considered as fixed effects.

All models took into account the correlated error between measurements made on the same individual as a random effect. For Models 3 and 4, another level of random effect was considered: the interaction individual $\times$ day. We selected the covariance structure for each model using the Akaike Information Criterion (AIC). For Models 1 and 2, a compound symmetry covariance structure was used. For Model 3, a firstorder autoregressive correlation between measurements was considered. For Model 4, because the reabsorption experiment lasted $60 \mathrm{~min}$ it was possible to use an unconstrained covariance structure to model correlation error between measurements made over the same period. 
The significance of variance heterogeneity was examined using a likelihood ratio test (LRT), and the related covariance parameter was removed from subsequent analyses if not significant. Restricted maximum likelihood estimates were used to test the significance of the fixed effects. The significance of explanatory terms was examined using non-sequential $F$ tests based on the Kenward-Roger correction for degrees of freedom (SAS Institute, version 9.1.2 software). Non-significant interactions were then successively removed to obtain the final model. All statistical analyses were carried out using SAS (SAS Institute, version 9.1.2) software.

\section{RESULTS}

\section{qPCR results and clinical chytridiomycosis}

Real-time PCR revealed that the swabbed surviving control newts were negative for $B d$. Furthermore, all dead control newts were also negative for the pathogen (Table 1). Repeated exposure to Bd infected $40 \%$ of the 15 surviving exposed newts, and all dead exposed newts were positive for $B d$ (Table 1). We can assume that the dead exposed newts died of chytridiomycosis. Indeed, all of these individuals were infected, and genome equivalents showed that the number of $B d$ zoospores was around 20 times greater than for surviving exposed newts (Table 1). In addition, all exposed newts, i.e. surviving as well as dead newts, showed a sloughing of the whole body (from the ventral abdomen, flanks, dorsum, legs and tail) versus only 2 control newts (pers. obs.).

Table 1. Lissotriton helveticus. Prevalence of chytrid infection and genome equivalents (GE) for all positive newts in this study. Prevalence was calculated as the proportion of individuals testing positive at $0.1 \mathrm{GE}$. GE are corrected for a $1 / 10$ dilution factor

\begin{tabular}{|lrcc|}
\hline & $\mathrm{n}$ & $\begin{array}{c}\% \text { positive } \\
(95 \% \mathrm{CI})\end{array}$ & $\mathrm{GE}( \pm \mathrm{SE})$ \\
\hline Control newts & & & \\
Living & 14 & $0(0-27)$ & $/$ \\
Dead & 8 & $0(0-48)$ & $/$ \\
Exposed newts & & & \\
Living & 15 & $40(17-67)$ & $1.13(0.25)$ \\
Dead & 7 & $100(52-100)$ & $20.35(10.87)$ \\
\hline
\end{tabular}

\section{Expt 1}

In Model 1, we did not detect any significant variance heterogeneity between treatments either on activity $\left(\mathrm{LRT}_{2 \mathrm{df}}=0.8, \mathrm{~ns}\right)$ or on postural adjustment $\left(\mathrm{LRT}_{2 \mathrm{df}}=5.4, \mathrm{p}=0.067\right)$. Neither the $\mathrm{W}_{0}$ of the newts nor the treatment they underwent affected their activity (Table 2). However, animals tended to be less active on Day 16 (Day 1 versus Day 16 for control newts: $0.12 \pm 0.02$ versus $0.09 \pm 0.02$; for exposed newts: $0.11 \pm 0.02$ versus $0.08 \pm 0.02$, moves $\mathrm{min}^{-1}$ $\pm \mathrm{SE}_{i}$ Table 2 ). Neither the $\mathrm{W}_{0}$ of animals, the treatment they underwent nor the day of measurement significantly affected the time spent in a given posture when inactive (Table 2). Newts did not modify their postural adjustment according to the treatment they experienced (control versus exposed newts on Day 1: $0.19 \pm 0.03$ versus $0.20 \pm 0.03$; on Day 16: $0.16 \pm 0.03$ versus $0.17 \pm 0.03$; adoption of ' $\mathrm{I}$ ' posture $\mathrm{min}^{-1} \pm \mathrm{SE}$; Table 2). Estimates of the random effects are available in Table S1 in the Supplement at www. int-res.com/articles/suppl/d104p215_supp.pdf.

\section{Expt 2}

Model 2 indicated that the ' $\mathrm{S}$ ' posture had a significantly lower TEWL rate than the 'I' posture (Table 3, Fig. 2). The model also showed that the TEWL rate of agar models reduced throughout the dehydration experiment (Table 3, Fig. 2), and lighter models had a lower TEWL rate than heavier ones (Table 3). Estimates of the random effects are available in Table S1.

\section{Expt 3}

In Model 3, according to the AIC score, an autoregressive correlation was more supported than a con- 
stant one to analyse the TEWL rate during dehydration experiments (AIC scores for autoregressive and constant correlations were -1232.9 and -1223.5, respectively). TEWL rates were significantly more variable among the exposed newts than among controls $\left(\mathrm{LRT}_{4 \mathrm{df}}=68.2, \mathrm{p}<0.001\right)$, and this variance heterogeneity was more salient for the second batch of measurements than for the first $\left(\mathrm{LRT}_{4 \mathrm{df}}=72.5, \mathrm{p}<\right.$ 0.001). No effect of treatment on the TEWL rate depending on the day of measurement was detected (Table 4, Fig. 3a,b): contrast analyses showed no significant difference between both treatments on Day 1 $\left(F_{1,86.7}=0.22 ; \mathrm{p}=0.64\right)$ and Day $16\left(F_{1,115}=3.62 ; \mathrm{p}=\right.$ 0.059). Nevertheless, while the TEWL rate did not significantly vary between the 2 measurement days in control newts $\left(F_{1,43.9}=0.23 ; \mathrm{p}=0.63\right)$, we detected a significantly higher TEWL rate on Day 16 in the case of the exposed newts $\left(F_{1,67.7}=10.08 ; p=0.002\right)$. However, the increase in TEWL rate in the exposed group, while statistically significant, was not biologically relevant, considering that the difference in water loss was about $0.9 \%$ of $\mathrm{W}_{0}$ over a $60 \mathrm{~min}$ period (Fig. 3a). The TEWL rate was constant over the duration of the desiccation experiments, regardless of the time period considered (Table 4, Fig. 3), but lighter animals had a lower TEWL rate than heavier ones (Table 4). Estimates of the random effects are available in Table S2 in the Supplement.

In Model 4, the unconstrained correlation structure was used to analyse the VWA rate during rehydration experiments (AIC scores for the unconstrained structure, the autoregressive and constant forms were 827.3, 863.6 and 857.5, respectively). We did not detect significant variance heterogeneity between treatments $\left(\mathrm{LRT}_{21 \mathrm{df}}=31.5, \mathrm{p}=\right.$ $0.0657)$, but the variance heterogeneity was significant between time periods $\left(\mathrm{LRT}_{21 \mathrm{df}}=45.1, \mathrm{p}=0.0017\right)$. The results of this analysis showed that exposed newts exhibited a significantly lower VWA rate than control newts, regardless of the measurement day (Table 4, Fig. 4). The difference was about $1.6 \%$ of $\mathrm{W}_{0}$ over a $60 \mathrm{~min}$ period for both measurement days (Fig. 4a). Moreover, the VWA rate declined as newts replenished their bodies with water (Table 4, Fig. 4), and the VWA rate was positively related to animal mass (Table 4). Estimates of the random effects are available in Table S3 in the Supplement.
Table 3. Lissotriton helveticus. Model 2 analysed for transepidermal water loss (TEWL) rate based on the posture of agar models. The model included 3 fixed effects (initial body mass: $\mathrm{W}_{0}$; posture: I' or 'S' shape; and successive measurements made within the desiccation period: time) together with the interactions between these factors. Non-significant interactions were all excluded from the final model. The model took into account the correlated error between measurements made on the same individual as a random effect (see Table S1 in the Supplement)

\begin{tabular}{|lrrr|}
\hline & \multicolumn{3}{c|}{ TEWL rate } \\
\cline { 2 - 3 } & $\mathrm{df}$ & $F$ & \multicolumn{1}{c|}{$\mathrm{p}$} \\
\hline $\mathrm{W}_{0}$ & $1,13.5$ & 20.75 & 0.0005 \\
Time & $1,24.1$ & 15.35 & 0.0006 \\
Posture & $1,19.9$ & 27.77 & $<0.0001$ \\
Time $\times$ Posture & $1,24.1$ & 5.24 & 0.0311 \\
\hline
\end{tabular}

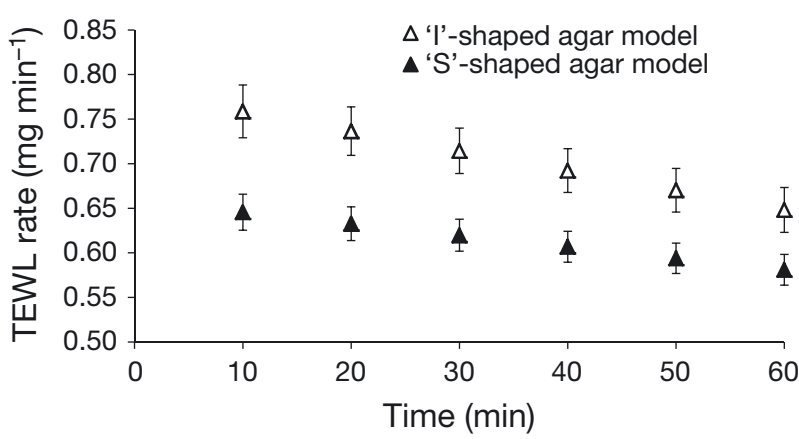

Fig. 2. Lissotriton helveticus. Transepidermal evaporative water loss rate (TEWL, mixed-models, $\mathrm{mg} \mathrm{min}^{-1} \pm \mathrm{SE}$ ) for a $60 \mathrm{~min}$ period for both the 'I'- and the 'S'-shaped agar models

Table 4. Lissotriton helveticus. Model 3 and Model 4 analyses for transepidermal water loss (TEWL) rate and ventral water absorption (VWA) rate, respectively. The models included 4 fixed effects (initial body mass: $\mathrm{W}_{0}$; treatment: control or exposed; day of measurement: Day 1 or 16; and successive measurements made within the desiccation period: time) together with the interactions between these factors. Non-significant interactions were all excluded from the final model. Two levels of random effect were considered. The models took into account the correlated error between measurements made on the same individual. Another level of random effect was considered: the interaction individual $\times$ day (see Tables S2 \& S3 in the Supplement)

\begin{tabular}{|c|c|c|c|c|c|c|}
\hline & \multicolumn{3}{|c|}{ TEWI rate } & \multirow[b]{2}{*}{ df } & \multirow{2}{*}{$\begin{array}{c}\text { VWA rate } \\
F\end{array}$} & \multirow{2}{*}{ e } \\
\hline & df & $F$ & $\mathrm{p}$ & & & \\
\hline Time & 1,328 & 1.70 & 0.1931 & 1,101 & 236.03 & $<0.0001$ \\
\hline $\mathrm{W}_{0}$ & $1,73.5$ & 4.92 & 0.0296 & $1,45.4$ & 71.63 & $<0.0001$ \\
\hline Day & $1,56.2$ & 6.60 & 0.0129 & $1,41.8$ & 1.23 & 0.2745 \\
\hline Treatment & $1,65.6$ & 1.19 & 0.2800 & $1,37.6$ & 25.22 & $<0.0001$ \\
\hline Treatment $\times$ Day & $1,53.6$ & 3.70 & 0.0599 & & & \\
\hline
\end{tabular}



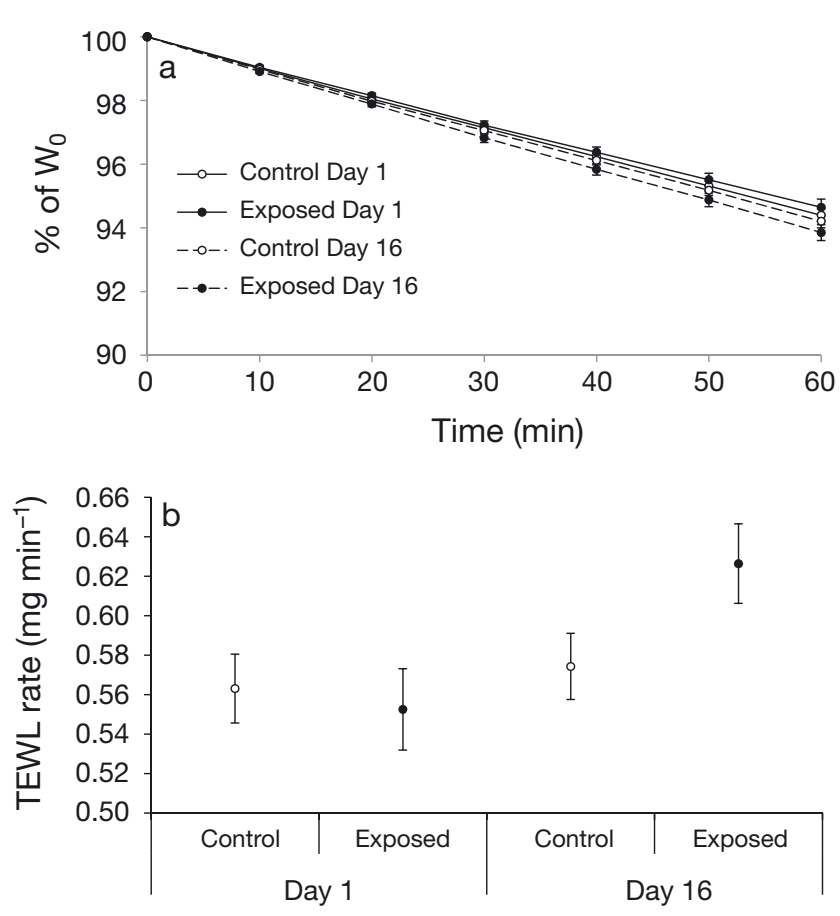

Fig. 3. Lissotriton helveticus. (a) Transepidermal evaporative water loss (TEWL, mean \% of the initial body mass $\mathrm{W}_{0} \pm \mathrm{SE}$ ) for a 60 min period for both control and exposed newts $24 \mathrm{~h}$ after initial exposure to Batrachochytrium dendrobatidis (Day 1) and $16 \mathrm{~d}$ after repeated exposures. \% of $\mathrm{W}_{0}$ denotes the percentage of the initial body mass. (b) TEWL rate (mixed-models, $\mathrm{mg} \mathrm{min} \mathrm{m}^{-1} \pm \mathrm{SE}$ ) for both treatments on Day 1 and Day 16

\section{DISCUSSION}

Adult male palmate newts expressed a restricted activity rate when exposed to desiccation stress. As shown in other salamander species exposed to desiccating conditions, inactivity is associated with a postural adjustment that consists of tightly coiling the body and the tail (Alvarado 1967, Gehlbach et al. 1969) to form an 'S' shape. Alvarado (1967) reported that inactive terrestrial long-toed salamanders Ambystoma macrodactylum and tiger salamanders A. tigrinum with an ' $\mathrm{S}$ '-shaped posture experienced a lower water loss rate than active animals. Our results on agar models also showed that the ' $\mathrm{S}$ ' posture improves water economy relative to the 'I' posture when inactive. The water economy of the ' $\mathrm{S}$ ' posture certainly reflects a reduction in the surface exposed to evaporation. Thus, our results suggest that restricted activity associated with water-conserving postures can be used as an emergency response by newts unable to escape from desiccating conditions to increase their chance of survival (Pough et al. 1983).

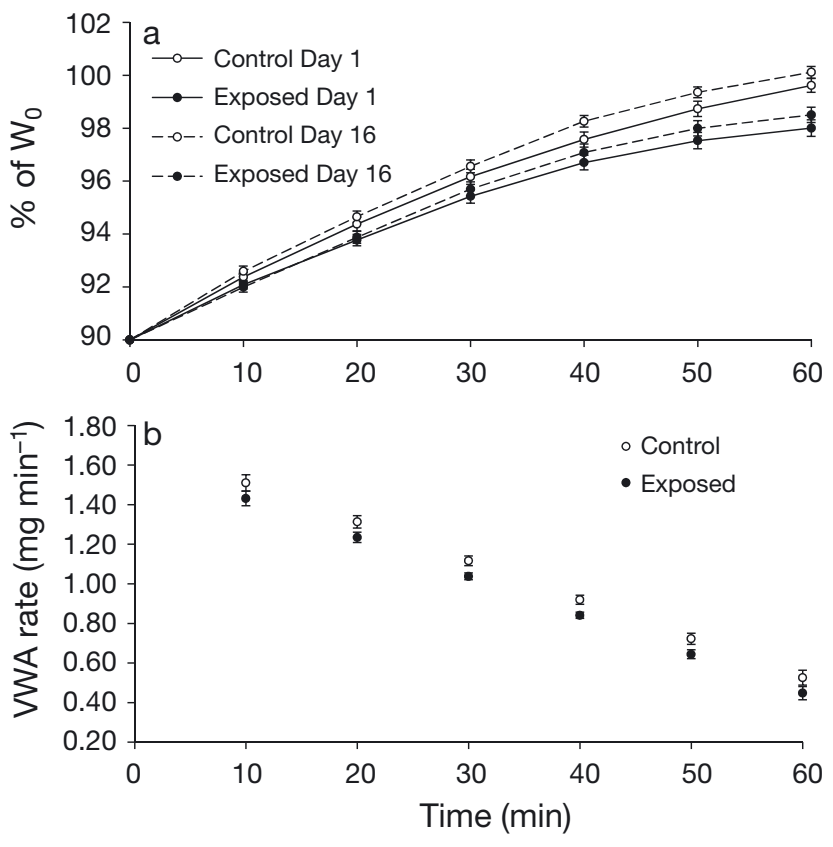

Fig. 4. Lissotriton helveticus. (a) Rehydration (mean \% of the initial body mass $\mathrm{W}_{0} \pm \mathrm{SE}$ ) for both control and exposed newts $24 \mathrm{~h}$ after initial exposure to Batrachochytrium dendrobatidis (Day 1) and $16 \mathrm{~d}$ after repeated exposures. \% of $\mathrm{W}_{0}$ denotes the percentage of initial body mass. (b) Deceleration of ventral water absorption rate (VWA, mixed-models, $\mathrm{mg} \mathrm{min} \mathrm{m}^{-1} \pm \mathrm{SE}$ ) for both control and exposed newts

Numerous studies have shown that exposure to $B d$ can lead to behavioural modifications in amphibians such as the expression of lethargic behaviours associated with abnormal and depressed postures (e.g. Bosch et al. 2001, Nichols et al. 2001, Carver et al. 2010). Our results do not show that exposure to $B d$ has a significant effect on activity and posture in the laboratory. In our experiment, the duration of exposure may have been insufficient to observe such lethargic and/or depressive behaviour in palmate newts. Furthermore, we found that the TEWL rate between treatments had not changed, although the difference in TEWL rate was significant in the exposed newts between the 2 measurement days. It therefore seems unlikely that $B d$ impedes the TEWL in newts, as suggested by Carver et al. (2010) in infected hylid frogs Litoria raniformis. In contrast, our results suggest that $B d$ has an impact on the ventral rehydration capacity of newts. $B d$ exposure slowed down the VWA rate, although the decrease was quite low, given that the difference in water uptake between groups was about $1.6 \%$ of $\mathrm{W}_{0}$ over a 60 min period. These results are consistent with the study of Carver et al. (2010) on infected hylid frogs, where a difference in water uptake of about 2 to $3 \%$ of $\mathrm{W}_{0}$ over a $60 \mathrm{~min}$ period was found 1 wk after inoculation with $B d$. 
Surprisingly, in our study, VWA was impeded $24 \mathrm{~h}$ after the first exposure to the pathogen without modifications until Day 16. Such an impact of $B d$ seems to reflect a disruption in the water uptake function of the ventral epidermis and suggests the action of a fungal toxin or other active compounds, rather than $B d$ itself. Indeed, $B d$ takes a few days to establish itself in the amphibian epidermis, its whole life cycle taking 4 to $5 \mathrm{~d}$ (Berger et al. 2005), and may produce lethal toxins either before or after infection (Blaustein et al. 2005). Furthermore, the study by Rosenblum et al. (2008) supports the role of a fungal toxin in the pathogenesis of $B d$, which may be driven by zoospores and zoosporangial secretions. More interestingly, the recent in vitro study by Brutyn et al. (2012) reported rapid (less than $4 \mathrm{~h}$ ) alterations in the structural integrity of the epidermis in Xenopus laevis after exposure to $B d$ zoospore secretions. As amphibian skin is physiologically active, disruption of epidermal structure through toxicity can compromise a number of critical skin functions including the ability to rehydrate or osmoregulate (Voyles et al. 2009, 2012, Carver et al. 2010, Marcum et al. 2010, Rosenblum et al. 2012). However, the exact mechanisms of VWA disruption in the palmate newt are still unknown. In White's tree frogs Litoria caerulea infected with $B d$, a disruption in electrolyte ion transport was found (Voyles et al. 2009), suggesting an epidermal electrolyte channel disruption (Voyles et al. 2009) and a decrease in ion channel gene expression (Rosenblum et al. 2012). In amphibians, rapid VWA is dependent on water channels inserted into the epidermal layers (i.e. aquaporins; see Connolly et al. 1998, Hasegawa et al. 2003, Suzuki et al. 2007). We can assume that VWA is impeded by $B d$ through an epidermal aquaporin disruption. However, the distribution of aquaporins in the epidermis remains to be established in urodeles. Further experiments are needed to investigate whether a reduction in rehydration ability in amphibians is due to an inhibition of epidermal aquaporins.

Our results, together with those of Voyles et al. (2007, 2009, 2012), Carver et al. (2010), Marcum et al. (2010) and Rosenblum et al. (2012), support the epidermal dysfunction hypothesis, which suggests that $B d$ compromises the ability of amphibians to osmoregulate or rehydrate. Such disruption of a crucial physiological process, even when small, can at least alter the adaptability of amphibians during their terrestrial phase in the wild and even their survival, especially in the context of a warming climate and prolonged or intensified drought events. This refers to the climate-linked epidemic hypothesis (e.g.
Pounds \& Crump 1994, Lampo et al. 2006, Pounds et al. 2006) and the drought-linked chytridiomycosis hypothesis (e.g. Burrowes et al. 2004, Lampo et al. 2006, Kriger 2009), which propose that abnormal climatic conditions can exacerbate chytridiomycosis outbreaks. However, these hypotheses remain highly controversial (Alford et al. 2007, Lips et al. 2008, Rohr et al. 2008, Kriger 2009). As stated by Kriger (2009), these hypotheses are inconsistent with our current knowledge of $B d$ physiology and ecology, and that dry conditions should reduce the severity of the pathogen. Nevertheless we have evidence that droughts actually increase outbreaks (Burrowes et al. 2004, Lampo et al. 2006). We can ask whether such impacts on transepidermal water exchanges by $B d$ in the palmate newt are sufficient to cause mortality in a climate change context. However, we are not in a position yet to answer this question, and further experiments are needed to conclude a link between climate change and the physiological effects of $B d$ on this species.

Acknowledgements. We thank E. Pérez Broto and C. Brustel for their valuable help and support in the field and laboratory. We are grateful to M. C. Fisher and T. W. J. Garner for providing the $B d$ strain and T. Colin for providing the $L$. helveticus agar model picture. We also thank P. Hulmes and 3 anonymous referees who helped to improve this manuscript. This study was supported by a grant from the Ministère de l'Enseignement Supérieur et de la Recherche and was conducted with the approval of the Préfecture de l'Isère (decision 2010-04110) and the Ethical Committee of University Lyon 1 in accordance with the current French laws and with the approval of the Director of Veterinary Services (DSV permit no. 692661232).

\section{LITERATURE CITED}

Alford RA, Bradfield KS, Richards SJ (2007) Global warming and amphibian losses. Nature 447:E3-E4

> Alvarado RH (1967) The significance of grouping on water conservation in Ambystoma. Copeia 1967:667-668

> Berger L, Speare R, Daszak P, Green DE and others (1998) Chytridiomycosis causes amphibian mortality associated with population declines in the rain forests of Australia and Central America. Proc Natl Acad Sci USA 95: 9031-9036

Berger L, Hyatt AD, Speare R, Longcore JE (2005) Life cycle stages of the amphibian chytrid Batrachochytrium dendrobatidis. Dis Aquat Org 68:51-63

Blaustein AR, Romansic JM, Scheessele EA, Han BA, Pessier AP, Longcore JE (2005) Interspecific variation in susceptibility of frog tadpoles to the pathogenic fungus Batrachochytrium dendrobatidis. Conserv Biol 19: 1460-1468

Blaustein AR, Gervasi SS, Johnson PT, Hoverman JT, Belden LK, Bradley PW, Xie GY (2012) Ecophysiology meets conservation: understanding the role of disease in 
amphibian population declines. Philos Trans R Soc Lond B Biol Sci 367:1688-1707

- Bosch J, Martinez-Solano I, Garcia-Paris M (2001) Evidence of a chytrid fungus infection involved in the decline of the common midwife toad (Alytes obstetricans) in protected areas of central Spain. Biol Conserv 97:331-337

> Boyle DG, Boyle DB, Olsen V, Morgan JAT, Hyatt AD (2004) Rapid quantitative detection of chytridiomycosis (Batrachochytrium dendrobatidis) in amphibian samples using real-time Taqman PCR assay. Dis Aquat Org 60:141-148

> Brutyn M, D'Herde K, Dhaenens M, Van Rooij P and others (2012) Batrachochytrium dendrobatidis zoospore secretions rapidly disturb intercellular junctions in frog skin. Fungal Genet Biol 49:830-837

> Burrowes PA, Joglar RL, Green DE (2004) Potential causes for amphibian declines in Puerto Rico. Herpetologica 60: $141-154$

Carey C (2000) Infectious disease and worldwide declines of amphibian populations, with comments on emerging diseases in coral reef organisms and in humans. Environ Health Perspect 108:143-150

> Carey C, Cohen N, Rollins-Smith L (1999) Amphibian declines: an immunological perspective. Dev Comp Immunol 23:459-472

Carver S, Bell BD, Waldman B (2010) Does chytridiomycosis disrupt amphibian skin function? Copeia 2010:487-495

> Connolly DL, Shanahan CM, Weissberg PL (1998) The aquaporins. A family of water channel proteins. Int $\mathrm{J}$ Biochem Cell Biol 30:169-172

> Daszak P, Berger L, Cunningham AA, Hyatt AD, Green DE, Speare R (1999) Emerging infectious diseases and amphibian population declines. Emerg Infect Dis 5: 735-748

> Daszak P, Cunningham AA, Hyatt AD (2003) Infectious disease and amphibian population declines. Divers Distrib 9:141-150

Dejean T, Miaud C, Ouellet M (2010) La chytridiomycose: une maladie émergente des amphibiens. Bull Soc Herpetol Fr 134:27-46

- Farrer RA, Weinert LA, Bielby J, Garner TWJ and others (2011) Multiple emergences of genetically diverse amphibian-infecting chytrids include a globalized hypervirulent recombinant lineage. Proc Natl Acad Sci USA 108:18732-18736

> Fisher MC, Henk DA, Briggs CJ, Brownstein JS, Madoff LC, McCraw SL, Gurr SJ (2012) Emerging fungal threats to animal, plant and ecosystem health. Nature 484:186-194

Garner TWJ, Walker S, Bosch J, Leech S, Rowcliffe JM, Cunningham AA, Fisher MC (2009) Life history tradeoffs influence mortality associated with the amphibian pathogen Batrachochytrium dendrobatidis. Oikos 118:783-791

> Garner TWJ, Rowcliffe JM, Fisher (2011) Climate change, chytridiomycosis or condition: an experimental test of amphibian survival. Glob Change Biol 17:667-675

Gehlbach FR, Kimmel JR, Weems WA (1969) Aggregations and body water relations in tiger salamanders (Ambystoma tigrinum) from the Grand Canyon rims, Arizona. Physiol Zool 42:173-182

> Harvell CD, Mitchell CE, Ward JR, Altizer S, Dobson AP, Ostfeld RS, Samuel MD (2002) Climate warming and disease risks for terrestrial and marine biota. Science 296: 2158-2162

> Hasegawa T, Tanii H, Suzuki M, Tanaka S (2003) Regulation of water absorption in the frog skins by two vasotocin- dependent water-channel aquaporins, AQP-h2 and AQP-h3. Endocrinology 144:4087-4096

Kiesecker JM, Blaustein AR (1995) Synergism between UV$B$ radiation and a pathogen magnifies amphibian embryo mortality in nature. Proc Natl Acad Sci USA 92: 11049-11052

> Kiesecker JM, Blaustein AR, Belden LK (2001) Complex causes of amphibian population declines. Nature 410: $681-684$

Kriger KM (2009) Lack of evidence for the drought-linked chytridiomycosis hypothesis. J Wildl Dis 45:537-541

Lampo M, Rodriguez-Contreras A, La Marca E, Daszak P (2006) A chytridiomycosis epidemic and a severe dry season precede the disappearance of Atelopus species from the Venezuelan Andes. Herpetol J 16:395-402

Laurance WF, McDonald KR, Speare R (1996) Epidemic disease and the catastrophic decline of Australian rain forest frogs. Conserv Biol 10:406-413

Lillywhite HB (2006) Water relations of tetrapod integument. J Exp Biol 209:202-226

Lips KR, Diffendorfer J, Mendelson JR III, Sears MW (2008) Riding the wave: reconciling the roles of disease and climate change in amphibian declines. PLoS Biol 6:e72

Luquet E, Garner TWJ, Léna JP, Bruel C and others (2012) Genetic erosion in wild populations makes resistance to a pathogen more costly. Evolution 66:1942-1952

Marcum RD, St-Hilaire S, Murphy PJ, Rodnick KJ (2010) Effects of Batrachochytrium dendrobatidis infection on ion concentrations in the boreal toad Anaxyrus (Bufo) boreas boreas. Dis Aquat Org 91:17-21

Nichols DK, Lamirande EW, Pessier AP, Longcore JE (2001) Experimental transmission of cutaneous chytridiomycosis in dendrobatid frogs. J Wildl Dis 37:1-11

$>$ Pessier AP, Nichols DK, Longcore JE, Fuller MS (1999) Cutaneous chytridiomycosis in poison dart frogs (Dendrobates spp.) and White's tree frogs (Litoria caerulea). J Vet Diagn Invest 11:194-199

> Pough FH, Taigen TL, Stewart MM, Brussard PF (1983) Behavioural modification of evaporative water loss by a Puerto Rican frog. Ecology 64:244-252

> Pounds JA, Crump ML (1994) Amphibian declines and climate disturbance: the case of the golden toad and the harlequin frog. Conserv Biol 8:72-85

Pounds JA, Bustamante MR, Coloma LA, Consuegra JA and others (2006) Widespread amphibian extinctions from epidemic disease driven by global warming. Nature 439: 161-167

Rachowicz LJ, Hero JM, Alford RA, Taylor JW and others (2005) The novel and endemic pathogen hypotheses: competing explanations for the origin of emerging infectious diseases of wildlife. Conserv Biol 19:1441-1448

Rohr JR, Raffel TR, Romansic JM, McCallum H, Hudson PJ (2008) Evaluating the links between climate, disease spread, and amphibian declines. Proc Natl Acad Sci USA 105:17436-17441

> Rosenblum EB, Stajich JE, Maddox N, Eisen MB (2008) Global gene expression profiles for life stages of the deadly amphibian pathogen Batrachochytrium dendrobatidis. Proc Natl Acad Sci USA 105:17034-17039

Rosenblum EB, Poorten TJ, Settles M, Murdoch GK (2012) Only skin deep: shared genetic response to the deadly chytrid fungus in susceptible frog species. Mol Ecol 21: 3110-3120

Schrag SJ, Wiener P (1995) Emerging infectious diseases: What are the relative roles of ecology and evolution? 
Trends Ecol Evol 10:319-324

Shoemaker VH, Nagy KA (1977) Osmoregulation in amphibians and reptiles. Annu Rev Physiol 39:449-471

Shoemaker VH, Hillman SS, Hillyard SD, Jackson DC, McClanahan LL, Withers PC, Wygoda ML (1992) Exchange of water, ions, and respiratory gases in terrestrial amphibians. In: Feder E, Burggren WW (eds) Environmental physiology of the amphibians. University of Chicago Press, Chicago, IL, p 125-150

Solomon SD, Qin D, Manning M, Chen Z and others (eds) (2007) Climate change 2007: the physical science basis. Contribution of Working Group I to the 4th Assessment Report of the Intergovernmental Panel on Climate Change. Cambridge University Press, Cambridge and New York, NY

Spotila JR, Berman EN (1976) Determination of skin resistance and the role of skin in controlling water loss in amphibians and reptiles. Comp Biochem Physiol A Physiol 55:407-411

Spotila JR, O'Connor MP, Bakken GS (1992) Biophysics of heat and mass transfer. In: Feder E, Burggren WW (ed) Environmental physiology of the amphibians. University of Chicago Press, Chicago, IL, p 59-80

Stuart SN, Chanson JS, Cox NA, Young BE, Rodrigues ASL,

Editorial responsibility: Alex Hyatt,

Geelong, Victoria, Australia
Fishman DL, Waller RW (2004) Status and trends of amphibian declines and extinctions worldwide. Science 306:1783-1786

Suzuki M, Hasegawa T, Ogushi Y, Tanaka S (2007) Amphibian aquaporins and adaptation to terrestrial environments: a review. Comp Biochem Physiol A Mol Integr Physiol 148:72-81

- Thomas CD, Cameron A, Green RE, Bakkenes M and others (2004) Extinction risk from climate change. Nature 427: 145-148

Viborg AL, Rosenkilde P (2004) Water potential receptors in the skin regulate blood perfusion in the ventral pelvic patch of toads. Physiol Biochem Zool 77:39-49

Voyles J, Berger L, Young S, Speare R and others (2007) Electrolyte depletion and osmotic imbalance in amphibians with chytridiomycosis. Dis Aquat Org 77: 113-118

> Voyles J, Young S, Berger L, Campbell C and others (2009) Pathogenesis of chytridiomycosis, a cause of catastrophic amphibian declines. Science 326:582-585

Voyles J, Vredenburg VT, Tunstall TS, Parker JM, Briggs CJ, Rosenblum EB (2012) Pathophysiology in mountain yellow-legged frogs (Rana muscosa) during a chytridiomycosis outbreak. PLoS ONE 7:e35374

Submitted: May 30, 2012; Accepted: March 25, 2013

Proofs received from author(s): May 29, 2013 